\title{
A randomized trial of intravenous labetalol \& oral nifedipine in severe pregnancy induced hypertension
}

\section{Badal Dhali $^{1, *}$, Shritanu Bhattacharya ${ }^{1}$, Rajendra Prasad Ganguly ${ }^{1}$, Shrirupa Bandyopadhyay ${ }^{2}$, Mousumi Mondal ${ }^{3}$, Mousumi Dutta ${ }^{1}$}

\author{
${ }^{1}$ Department of Obstetrics \& Gynecology, RGKMC\&H, Kolkata, India \\ ${ }^{2}$ Department of Obstetrics \& Gynecology, Lady Duffrin Hospital, Kolkata, India \\ ${ }^{3}$ Department of Microbiology, I.P.G.M.E\&R, Kolkata, India
}

Received: 3 December 2012

Accepted: 14 December 2012

\section{*Correspondence:}

Dr. Badal Dhali

E-mail: dhali.badal@gmail.com

\begin{abstract}
Background: Hypertension is the most frequently encountered medical disorder in obstetrics practice \& remain a major cause of maternal, fetal \& neonatal morbidity \& mortality. The present study was undertaken to compare the time taken to reach the therapeutic goal blood pressure after using intravenous labetalol \& oral nifedipine in severe pregnancy induced hypertension.

Methods: Randomly allocated patients received labetalol $20 \mathrm{mg}$ initially, followed by escalating doses of 40, 80, 80 $\& 80 \mathrm{mg} \&$ a placebo tablet every 20 minutes or initially nifedipine tablet $10 \mathrm{mg}$ orally with repeated doses of $20 \mathrm{mg}$ every 20 minutes up to 5 doses \& intravenous placebo $0.9 \%$ isotonic saline until the therapeutic goal blood pressure, Systolic $\leq 150 \mathrm{mmHg} \&$ diastolic $\leq 100 \mathrm{mmHg}$ was achieved. Primary and secondary outcomes like the time interval required to achieve a blood pressure of $\leq 150 / 100 \mathrm{mmHg}$ and urinary output, agent failure \& adverse effects respectively were reported.

Results: Patients received oral nifedipine achieved the goal therapeutic blood pressure more rapidly in $28.2 \pm 11.7$ minutes (mean $\pm \mathrm{SD})$ as compared with $48.4 \pm 23.5$ minutes in those received intravenous labetalol $(p=0.001)$. The nifedipine group also required significantly fewer doses $(3.5 \pm 0.5$ vs $4.5 \pm 1.5 ; p=0.001)$ to reach the goal blood pressure. Urine output was significantly increased $(p<0.001)$ at one hour after nifedipine therapy $(95.6 \pm 1.2)$ compared with labetalol $(41.9 \pm 1.6 \mathrm{ml}) \&$ remained significantly increased at 4,8,16\&24 hours after initial therapy. Few adverse effects were reported but not significant. No patients required cross over therapy.

Conclusions: Oral nifedipine \& intravenous labetalol regimens are effective in the management of severe hypertension in pregnancy; however nifedipine controls hypertension more rapidly $\&$ is associated with a significant increase in urinary output.
\end{abstract}

Keywords: Severe pregnancy induced hypertension, Nifedipine, Labetalol

\section{INTRODUCTION}

Hypertension is the most frequently encountered medical disorder in obstetrics practice \& remain a major cause of maternal, fetal \& neonatal morbidity \& mortality not only in less developed but also in the industrialized countries. Among commonly used drugs for pregnancy induced hypertension (PIH), Hydralazine was temporarily withdrawn from the market in the early 1990s; Methyldopa may take a few days for onset of hypotensive effect, \& so rapid dosage changes in the first 2 to 3 days should not be undertaken. Recently mostly used drugs suggested from literature include nifedipine \& labetalol hydrochloride. Both nifedipine \& labetalol have demonstrated comparable efficacy \& a lower risk of overshoot hypotension \& fetal distress when compared with hydralazine in randomized clinical trials. ${ }^{1,2}$ To date there have been few randomized double blind trial of oral nifedipine \& intravenous labetalol in the acute management of hypertensive emergencies of pregnancy. Authors conclusion as per Cochrane review 2006 was that, pregnant women with very high blood pressure (hypertension) who take antihypertensive drugs can reduce their blood pressure, but the most effective antihypertensive drug is unknown. The review of 24 trials 
including 2949 women found that, while antihypertensive drugs lower blood pressure, there is not enough evidence to show which drug is most effective when taken by pregnant women with hypertension. Further research into the effects of antihypertensive drug is needed. ${ }^{3}$ The objective of our study was to compare the time taken to reach the therapeutic goal after using intravenous labetalol \& oral nifedipine in severe pregnancy induced hypertension.

\section{METHODS}

In this double blind, prospective, randomized study, the admitted patients in the labour room \& antenatal ward at the Eden Hospital, Calcutta Medical College with the diagnosis of severe PIH during a 23 month period were recruited for the study.

The study protocol was approved by the thesis ethical committee of the study institution, \& the written informed consent was taken from all the study participants. Patients were eligible for inclusion if they were 20 to 35 years old $\& \geq 22$ week's gestation. Enrollment occurred antepartum, intrapartum, \& within 24 hours postpartum, but the patients of eclampsia, known heart diseases, bronchial asthma, \& exposure to either study drugs in 24 hours of enrollment were excluded from our study.

The patients were then randomly allocated as per the sequence of computer generated randomization $\log \&$ placed in numbered sealed envelopes with two packages: $\mathrm{x} \& \mathrm{y}$. Injection labetalol vials $(5 \mathrm{mg} / \mathrm{ml})$ \& inactive placebo tablets, which were identical to oral nifedipine tablets, or $0.9 \%$ isotonic sodium chloride solution in a 60 ml syringe \& $10 \mathrm{mg}$ nifedipine tablets were labelled package $\mathrm{x}$. Package y contained the opposite regimen, \& which was considered when crossover is needed. Envelopes were opened by a ward nurse who was in the research team, \& both the physician \& patients were blinded as to the treatment given.

Severe PIH was defined as a sustained systolic blood pressure of $\geq 160 \mathrm{mmHg} \&$ diastolic blood pressure of $\geq 110 \mathrm{mmHg}$ on repeat measurement of 30 minutes apart in a lateral recumbent position with head of the bed elevation not exceeding 15 degree.

Once patients were enrolled, vital signs were recorded every 30 minutes, including blood pressure measurement by a mercury columns sphygmomanometer. The blood pressure cuff width was $15 \mathrm{~cm} \&$ the length of the cuff was about 1.5 times mid arm circumference. Volumes of urine output were recorded after collected in the urobag through Foleys catheter for 24 hours after the initial dosing. Monitoring of the fetal heart rate \& it's any abnormalities were noted \& also the maternal adverse effects like eclampsia, stroke, heart failure \& decreased urine output were recorded. Additional neonatal outcome included 5 minutes Apgar score of $<7$ \& NICCU admission were recorded.

Patients randomized to intravenous labetalol, received 20 $\mathrm{mg}$ initially, followed by escalating doses of $40 \mathrm{mg}, 80$ $\mathrm{mg}, \&$ then $80 \mathrm{mg}$ every 20 minutes until the therapeutic goal blood pressure systolic $\leq 150 \mathrm{mmHg}$ \& diastolic $\leq 100 \mathrm{mmHg}$ was achieved, or for a maximum of five doses.

Patients randomized to oral nifedipine received $10 \mathrm{mg}$ initially, with repeated doses of $20 \mathrm{mg}$ every 20 minutes for up to a maximum of 5 doses, or until the goal blood pressure were achieved. The dosing regimens for each study medication correspond with the regimens from two previous clinical trials. ${ }^{1,2}$ Corresponding placebos either $0.9 \%$ isotonic saline or inactive tablets were given simultaneously in each regimen. It was decided, if the therapeutic goal blood pressure was not achieved after 5 doses, blinded crossover would be done with the study medication. If the therapeutic blood pressure goal was still not achieved after 5 cross over doses, the open label treatment would be done. However in our study, no case required any crossover treatment.

The primary outcome was the time interval required to achieve the goal therapeutic systolic blood pressure of $\leq 150 \mathrm{mmHg} \&$ diastolic $\leq 100 \mathrm{mmHg}$. Secondary outcomes analyzed included urinary output, agent failure, \& maternal adverse effects like eclampsia, decreased urine output, stroke, \& heart failure. Additionally fetal heart rate abnormality, 5 minutes Apgar scores of $<7 \&$ NICCU admission were analyzed as secondary outcomes as infant's adverse effects.

To detect a $20 \%$ difference in the time interval required to achieve the goal blood pressure with alpha $=0.05 \&$ beta $=0.2$, it was determined that 50 patients would be needed in each study group.

Numerical data were analyzed by unpaired test \& the categorical variables were analyzed by Fischer exact test or chi-square test, whichever is applicable. The level of significance was $p<0.05 \&$ the statcal version 11 software was used for statistical analysis.

\section{RESULTS}

The randomized hundred patients were divided into two groups, one is labetalol group \& other is nifedipine group. The groups were similar with respect to maternal age, parity, body weight, mean systolic and mean diastolic blood pressure at the time of enrollment (Table $1)$.

Patients received oral nifedipine achieved the goal therapeutic blood pressure more rapidly in $28.2 \pm 11.7$ minutes (mean $\pm \mathrm{SD}$ ) as compared with $48.4 \pm 23.5$ minutes in those received intravenous labetalol $(p=0.001)$. The nifedipine group also required significantly fewer doses 
( $3.5 \pm 0.5$ vs. $4.5 \pm 1.5 ; p=0.001)$ to reach the goal blood pressure. Both drugs were ultimately effective in reaching the therapeutic goal because there were no failures requiring crossover in either study group.

Significant \& persistent increase in urine output was noted in nifedipine treatment group $\&$ that was recorded at $1,4,8,16, \& 24$ hours after the initial dosing (Table 2).

A few adverse maternal effects were noted. A single patient in each study group experienced heart failure, otherwise the occurrence of eclampsia, stroke, \& decreased urine output were experienced a little bit higher in frequency in labetalol group in comparison to nifedipine group. All the adverse effects were treated promptly accordingly, \& no death was recorded so far. Additionally there were no significant differences in both the study groups regarding the fetal heart rate abnormality, 5-minutes Apgar scores of $<7$ \& NICCU admission (Table 3).
Enrollment

Randomized

Allocation

Follow up

Analysis
Patient's eligible for enrollment $(n=110)$

Excluded-10 (4-eclampsia, 2-heart disease, 1-bronchial asthma \& 3-received either study drugs within 24 hrs. of enrollment)

Randomized $(n=100)$

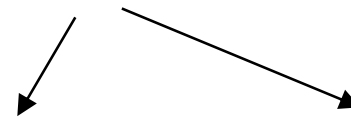

Received nifedipine $(n=50) \quad$ Received labetalol $(n=50)$

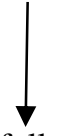

Lost to follow up $=0$

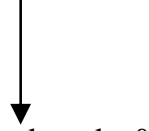

Completed study \&

Analysed $(n=50)$

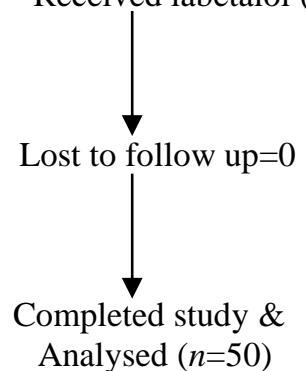

Figure 1: Patient's flow chart.

Table 1: Differences of variables of maternal age, weight, parity \& blood pressure.

\begin{tabular}{|c|c|c|c|}
\hline Variable & $\begin{array}{c}\text { Labetalol }(\boldsymbol{n}=\mathbf{5 0}) \\
\text { mean } \pm \mathrm{SD}\end{array}$ & $\begin{array}{c}\text { Nifedipine }(n=50) \\
\text { mean } \pm \text { SD }\end{array}$ & $\begin{array}{c}\text { Statistical } \\
\text { significance }(p)\end{array}$ \\
\hline Maternal age (years) & $24.3 \pm 1.2$ & $23.7 \pm 1.4$ & 0.024 \\
\hline Maternal weight (kg) & $66.2 \pm 1.1$ & $66.6 \pm 1.3$ & 0.100 \\
\hline \multicolumn{4}{|l|}{ Parity } \\
\hline Primi & $41(82 \%)$ & $40(80 \%)$ & \\
\hline Multi & $09(18 \%)$ & $10(80 \%)$ & 1.000 \\
\hline Systolic blood pressure & $163.2 \pm 1.5$ & $163.5 \pm 1.8$ & 0.365 \\
\hline Diastolic blood pressure & $110.7 \pm 1.4$ & $111.2 \pm 1.8$ & 0.124 \\
\hline
\end{tabular}


Table 2: Cumulative urine output.

\begin{tabular}{|cccc|}
\hline Duration $($ hrs $)$ & $\begin{array}{c}\text { Labetalol }(\mathrm{ml}) \\
\text { mean } \pm \text { SD }\end{array}$ & $\begin{array}{c}\text { Nifedipine }(\mathbf{m l}) \\
\text { mean } \pm \text { SD }\end{array}$ & $\begin{array}{c}\text { Statistical } \\
\text { significance }(\boldsymbol{p})\end{array}$ \\
\hline 1 & $41.9 \pm 1.6$ & $95.6 \pm 1.2$ & 0.001 \\
\hline 4 & $403.8 \pm 2.0$ & $705 \pm 2.1$ & 0.001 \\
\hline 8 & $747.8 \pm 2.3$ & $1160.2 \pm 1.8$ & 0.001 \\
\hline 24 & $1013.3 \pm 2.3$ & $1606 \pm 0.72$ & 0.001 \\
\hline
\end{tabular}

Table 3: Maternal and infant adverse outcomes.

\begin{tabular}{|c|c|c|c|}
\hline Adverse outcomes & Labetalol No (\%) & Nifedipine No (\%) & $p$-value \\
\hline \multicolumn{4}{|l|}{ Maternal } \\
\hline (a) Eclampsia & $3(6 \%)$ & $12 \%)$ & 0.617 \\
\hline (b) Decreased urine output & $5(10 \%)$ & $2(4 \%)$ & 0.436 \\
\hline (c) Stroke & $2(4 \%)$ & $1(2 \%)$ & 1.000 \\
\hline (d) Heart failure & $1(2 \%)$ & $1(2 \%)$ & 1.000 \\
\hline \multicolumn{4}{|l|}{ Infant } \\
\hline (a) FHR abnormality & $3(6 \%)$ & $6(12 \%)$ & 0.487 \\
\hline (b) 5 min. Apgar score $<7$ & $7(14 \%)$ & $3(6 \%)$ & 0.318 \\
\hline (c) NICCU admission & $4(8 \%)$ & $1(2 \%)$ & 0.362 \\
\hline
\end{tabular}

\section{DISCUSSION}

In this study, our data indicate that nifedipine achieved the therapeutic goal blood pressure more rapidly \& the needed number of doses was less than labetalol. Due to rapid onset, oral bioavailability, long action, $>90 \%$ metabolized in liver, excreted in urine \& very few side effects, the nifedipine pharmacokinetically could be a better drug for severe hypertension in pregnancy.

Previous study have demonstrated that nifedipine effectively lowers blood pressure without any apparent reduction in uteroplacental blood flow ${ }^{4,5} \&$ without any significant heart rate abnormalities. ${ }^{6,7}$ These extra benefits of nifedipine also support it as better option for treating the severe PIH patients.

There were no significant adverse events attributed to either drug regimens. However we were able to show the frequency of these outcomes. So far as maternal adverse outcome concerned, major adverse effects like eclampsia, stroke, heart failure \& decreased urine output were reported in either study group. This study is not powered enough to draw conclusion regarding the safety profile of the drugs.

There was no significant difference in fetal adverse outcomes like intrauterine fetal heart abnormality, Apgar score at 5 minutes $<7$, NICCU admission in both the groups. This finding is similar to the previous study. ${ }^{1,2}$
In severe $\mathrm{PIH}$, the patients may experience decreased urine output \& decreased renal perfusion, probably due to intravenous volume depletion. From previous study it was attributed that, nifedipine can enhance urine output after selective renal arteriolar vasodilatation \& which was reported in randomized controlled trials involving postpartum pre-eclamptic patients. ${ }^{8}$ In our study it was again proved that, patients treated with nifedipine had experienced a significant increase in urine output in comparison to labetalol treated patients. One hour after initial dosing, patients receiving nifedipine showed significant urine output volume than those of patients receiving labetalol. The increase in urine output persisted at least 24 hours after initial dosing.

Although it was studied that, there was increased risk of myocardial infarction in hypertensive patients treated with short acting calcium channel blocker ${ }^{9}$, the study had potential selection biases \& methodological limitations. The safety of the immediate release type calcium channel blockers used in pregnancy induced hypertension needs to be evaluated in further study. Even previously used hydralazine as a standard agent in severe PIH, had lost its popularity, because of its propensity to increase myocardial oxygen demand. Nifedipine has now been used safely in a number of obstetrical trials for the treatment of hypertensive emergencies ${ }^{1,8,10,11} \&$ as a tocolytic agent in several randomized clinical trials. ${ }^{1,2}$

In this study, the patients achieved the goal blood pressure after 2 to 3 doses of nifedipine \& because of this; the smaller concentration of nifedipine was 
insufficient to evaluate the tocolytic effect of nifedipine. ${ }^{13}$ Although both labetalol \& nifedipine are better alternative to hydralazine, the ability of nifedipine to control severe hypertension more rapidly without significant overshoot hypotension \& other maternal \& fetal side effects. The more favourable effect on urine output demonstrated by nifedipine may provide additional support for its use as an alternative agent for patients with the problem of urinary output.

\section{ACKNOWLEDGEMENTS}

We thank the colleagues \& staffs of the department of obstetrics \& gynecology, Eden hospital Calcutta, for their assistance in completing this study.

\section{Funding: No funding sources}

Competing interests: None declared

Ethical approval: The study was approved by the thesis ethical committee of the institution

\section{REFERENCES}

1. Fenakel K, Fenakel G, Appelman Z, Lurie S, Katz Z, Shoham Z, et al. Nifedipine in the treatment of severe preeclampsia. Obstet Gynecol 1991;77:3317.

2. Mabie W, Gonzalez A, Sibai B, Amon E. A comparative trial of labetalol \& hydralazine in the acute management of severe hypertension complicating pregnancy. Obstet Gynecol 1987;70:328-33.

3. Duley L, Henderson-Smart DJ, Meher S. Drugs for treatment of very high blood pressure during pregnancy. Cochrane Database Syst Rev 2006;(3):CD 001449.

4. Lindow S, Davies N, Davy D, Smith S. The effect of sublingual nifedipine on uteroplacental blood flow in hypertensive pregnancy. $\mathrm{Br} \mathrm{J}$ Obstet Gynecol 1988;95:1276-81.

5. Moretti M, Fairlie F, Axl S, Khoury A, Sibai B. The effect of nifedipine therapy on fetal placental Doppler waveforms in preeclampsia remote from term. Am J Obstet Gynecol 1990;163:1844-8.

6. Lurie S, Fenakel K, Freidman A. Effect of nifedipine on fetal heart rate in the treatment of severe pregnancy induced hypertension. Am J Perinatol 1990;7:285-6.

7. Walters N, Redman W. Treatment of severe pregnancy associated with hypertension with the calcium antagonist nifedipine. Br J Obstet Gynecol 1987;91:330-4.

8. Barton J, Hiett A, Conover W. The use of nifedipine during the postpartum period in patients with severe preeclampsia. Am J Obtet Gynecol 1990;162:788-92.

9. Psaty BM, Heckbert SR, Koepsell TD, et al. The risk of myocardial infarction associated with antihypertensive drug therapies. JAMA 1995;274:620-5.

10. Scardo JA, Vermillion ST, Hogg B, Newman RB. Hemodynamic effects of oral nifedipine in preeclamptic hypertensive emergencies. Am J Obstet Gynecol 1996;175:336-8.

11. Seabe SJ, Moodley J, Becker P. Nifedipine in acute hypertensive emergencies in pregnancy. S Afr Med J 1989;76:248-50.

12. Meyer WR, Randall HW, Graves WL. Nifedipine versus ritodrine for suppressing preterm labor. J Reprod Med 1990;35:649-53.

13. Papatsonis DN, Van Geijn HP, Ader HJ, Lange FM, Bleker OP, Dekker GA. Nifedipine and ritodrine in the management of preterm labor: a randomized multicenter trial. Obstet Gynecol 1997;90:230-4.

DOI: $10.5455 / 2320-1770 . i j r \operatorname{cog} 001912$

Cite this article as: Dhali $\mathrm{B}$, Bhattacharya S, Ganguly RP, Bandyopadhyay S, Mondal M, Dutta $\mathrm{M}$, et al. A randomized trial of intravenous labetalol \& oral nifedipine in severe pregnancy induced hypertension. Int $\mathbf{J}$ Reprod Contracept Obstet Gynecol 2012;1:42-6. 